IOS Press

\title{
Interview with H.E. Butti Ahmed Mohamed Bin Butti Al Qubaisi on leading SCAD and hosting IAOS 2016
}

\author{
Raba'a Baniyas \\ Director of Statistics Training Institute, Statistics Centre Abu Dhabi \\ E-mail:rmbaniyas@scad.ae
}

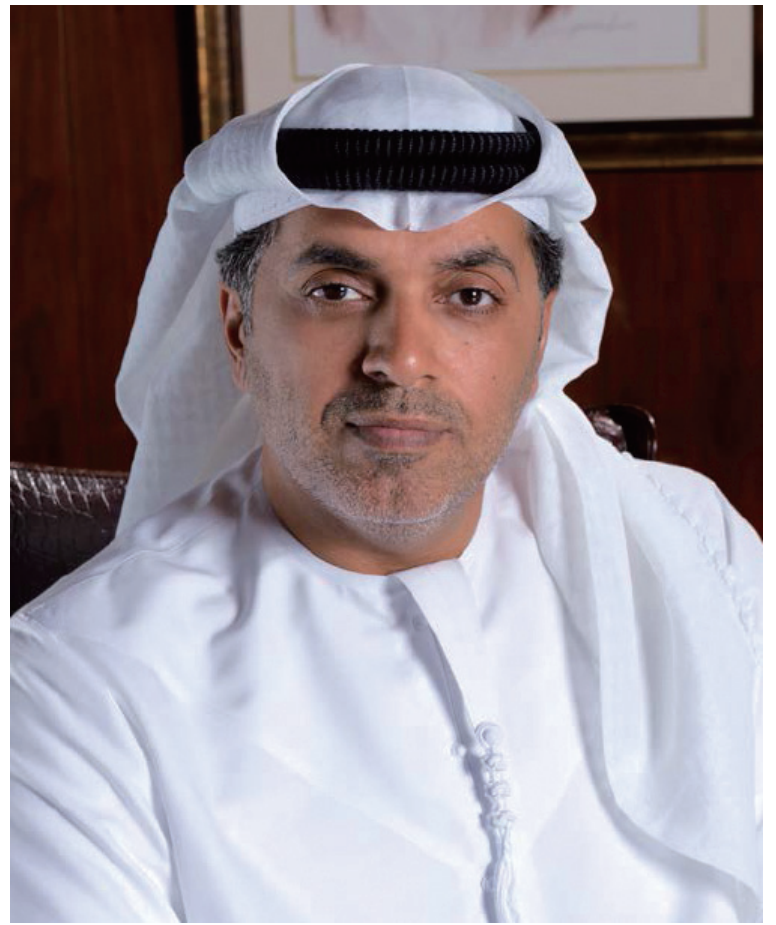

H.E. Butti Ahmed Mohamed Bin Butti Al Qubaisi is the founder and Director General of the Statistics Centre Abu Dhabi (SCAD). Established by law in 2008, SCAD is the official source of statistical data in Abu Dhabi Emirate. Tasked with the production, analysis and dissemination of all official statistics within its domain, SCAD is also responsible for the integration and harmonisation of statistics across other government entities, promoting the professional ethics of official statistics and ensuring the standardisation of methodological concepts and definitions. In the course of the past 25 years, His Excellency has served in a number of senior posts, including: Executive Director for Planning and Statistics at the Department of Economic Development, and Director of the Economic Division at the Department of Planning and Economy. In the late nineties, he was Coordinator for the Abu Dhabi Programme for Strategic Development 2020, in cooperation with the United Nations Development Programme (UNDP). He is also a member of the Abu Dhabi National Advisory Council, member of the SubCommittee on Population Structure, member of the Board of Abu Dhabi Centre for Corporate Governance, and member of the Abu Dhabi Food Security Committee. He holds a Master's Degree in Business Administration from Geneva, and a Bachelor's Degree in Public Administration from UAE University (1991).

\section{The Statistics Centre Abu Dhabi - leadership and innovation in statistics}

SCAD's mission is to work with partners to provide credible, innovative and high-quality statistics, to support decision-makers and other interested users, and contribute to the achievement of the sustainable development goals in the Emirate of Abu Dhabi. 
H.E. Butti Al Qubaisi, in his capacity as Director General of SCAD, leads the programme of surveys across the entire statistical value chain including the classification, collection, storage, analysis and dissemination of official statistics across the population, social, demographic, economic, environmental, agricultural and cultural domains. In so doing, His Excellency ensures the highest quality standards according to international best practice covering professional independence, objectivity, statistical confidentiality, appropriateness of cost and quality of statistics, and other fundamental principles of official statistics.

In this sense, His Excellency plays a pivotal role in connecting statistics to policy makers. His key role in the development of official statistics directly facilitates the use of evidence-based policy-making in the Emirate. His pioneering work in formulating plans, programmes and policies based on the realities of modern and accurate statistics have formed an important pillar for decision makers within government, academia, media, research, and throughout the wider community.

Following its establishment, the first major challenge for H.E. Butti Al Qubaisi was to oversee the preparation of the first SCAD Five-Year Strategic Plan. This involved the identification of priorities, the formation of focus points, and the setting of key performance goals; and represented a major leap in the comprehensive development of official statistics in the Emirate. His Excellency was able to make significant progress in building a statistical system capable of providing and producing robust statistical indicators that met business requirements, and the needs of decision-makers and other data users in the public and private sectors. Developments were carefully benchmarked against international standards and practices to ensure appropriate comprehensiveness, accuracy and timing.

An important measurement of success in this regard, and a source of great personal satisfaction for H.E. Butti Al Qubaisi, was the significant increase in the availability of high-quality official statistical indicators for the Emirate of Abu Dhabi, made possible by the strengthening of data production methods. Today, thanks to His Excellency's drive and determination, the number of established SCAD statistical indicators is well over 1,000 and the number of established SCAD publications - including statistical reports and specialised periodicals - exceeds 100 .

Centres of official statistics cannot operate in isolation. H.E. Butti Al Qubaisi was instrumental in forging strong bilateral relationships with around $35 \mathrm{Abu}$
Dhabi government entities and local bodies within the UAE, through a series of negotiated agreements.

In leading SCAD, H.E. Butti Al Qubaisi understood that a centre of official statistics is only as good as its people. To facilitate the rapid effectiveness and promote the importance of his organisation, His Excellency successfully recruited and subsequently led a number of internationally recognised statistical specialists to enhance the outputs and reputation of SCAD across all its domains. To foster statistical capacity building and promote operational sustainability, His Excellency almost single-handedly set up a statistical training institute dedicated to supporting official statistics. This resulted in improved technical competencies across data providers, producers and users - strengthening the statistical system of Abu Dhabi.

H.E. Butti Al Qubaisi has introduced a number of major organisational initiatives which have helped to shape the cultural identity of SCAD. These have strengthened SCAD's professional reputation both domestically and internationally, and have led to a number of personal achievements and prestigious awards.

\section{The Statistical Training Institute - promoting a culture of knowledge and education}

In addition to his SCAD leadership responsibilities, His Excellency is committed to broadening statistical literacy to include non-statisticians in government and the wider public. In 2011, realising the urgent need to improve statistical competencies across data providers, produces and users, and with full government support, H.E. Butti Al Qubaisi founded the Abu Dhabi Statistical Training Institute (STI) and its associated Scientific Committee drawn from all the major UAE Universities. Its vision to be a leading training institute, supporting the advancement of excellent statistical capabilities, and its mission to provide high quality, internationally recognised statistical training. Thanks to this pioneering work, His Excellency has built and continues to build a highly competent workforce to develop and manage SCAD operations; and is quickly becoming a highly reputable organisation regionally and globally. Focusing on the key values of putting the customer first, innovation and excellence, professionalism, and high quality standards, His Excellency has guided STI to deliver on the following core business areas:

- Delivering the training needs of the statistical community in Abu Dhabi 
- Focusing on the practical application of official statistics to meet the needs of data producers and users

- Providing integrated certified training modules to strengthen the statistical system of Abu Dhabi

- Building statistical capacity of government entities at emirate and federal level

- Forging key partnerships with statistical training institutes around the world

- Harnessing a wide network of leading international trainers in official statistics

Some of the key STI initiatives driven through by H.E. Butti Al Qubaisi include:

- Implementing statistical literacy programme to serve SCAD non-statisticians and wider UAE community

- Visiting schools and other institutes of learning to promote statistical knowledge and education

- Becoming an authorised centre for Royal Statistical Society examinations

- Introducing internal award schemes for data managers and data analysts

- Designing modular integrated certified training programme in official statistics

- Undertaking statistical leadership and management development training programmes

- Ensuring certification and accreditation by recognised international organisations and universities

- Increasing public and private sector participation in STI programmes

\section{The IBDAA Programme - promoting a culture of creativity}

Appreciating the importance of innovation and its contribution to institutional performance development, H.E. Butti Al Qubaisi, launched the 'IBDAA Innovation/Creativity' programme designed to encourage and motivate employees to think creatively about new ideas which can be implemented in the workplace. In the last year alone, over 400 ideas have been adopted to help develop the Centre from technical, administrative and social perspectives. This initiative has been officially recognised by the UK's foremost Association for the Promotion of Employees Involvement Programme (UK IDEAS). For three years' running (20132015), His Excellency has won the UK IDEAS highly prized Platinum Award for International Organisation of the Year for his work in encouraging creativity in the workplace.

\section{Geographic Information Systems - promoting excellent statistical technology}

In 2015, on behalf of SCAD, H.E. Butti Al Qubaisi received the International Award of Excellence in the use of GIS Applications for the second year in a row. These accolades were presented in the framework of the technology conferences organised by GISTEC, the official representative of many of the world's leading GIS companies. The prize is one of the highest international awards in the Middle East and North Africa in the field of geographic information systems, and allocated according to a points system that distinguishes various elements including innovation and leadership. Additionally, in 2013, His Excellency's work on the SCAD Portal led to the Award for Best Strategic Arabic Website by the Arab Academy Awards. In the same year, SCAD achieved an Excellence Award in GIS for innovative style at the GISWORX Conference, becoming the first government agency to deliver a technical paper at the event. In 2012, SCAD received the SAS Excellence in Government Award in the Middle East. In the same year, his Excellency was awarded the President's Award in GIS Strategy, provided by the Environmental Systems Research Institute (ESRI).

\section{Abu Dhabi Awards - promoting a culture of excellence}

H.E. Butti Al Qubaisi has been involved in the Abu Dhabi Award for Government Excellence in 2010, 2013 and 2015. This has resulted in a number of positive achievements for SCAD including top ten listings for the best government projects across the Emirate. In addition, His Excellency has supported individual successes including top ten listings for best new employee, management support, and customer service.

\section{International Relations - promoting a culture of global integration}

From SCAD's inception, H.E. Butti Al Qubaisi has promoted a culture of global integration through various international relations channels. This has enabled the identification of good practices, the exchange of ideas and experiences, and the enthusiastic participation in regional and global statistical capacity building projects. Thanks to His Excellency's efforts, SCAD has quickly become an active member of the world's 
statistical community, adding tangible value to international statistical conferences through knowledge sharing. His Excellency has built successful partnerships and signed Memoranda of Understanding with a number of leading global statistical organisations, including the Australian Bureau of Statistics (ABS), the Italian national statistical institute (ISTAT), the Korean national statistical institute (KOSTAT), and the German national statistical institute (DESTATIS).

\section{The International Association for Official Statistics 2016 - promoting a culture of statistical leadership}

H.E. Butti Al Qubaisi, on behalf of SCAD and Abu Dhabi, is extremely proud to be hosting the 2016 International Association for Official Statistics (IAOS) Conference, asserting that Abu Dhabi is firmly on the map as an excellent conference venue. Having quickly established SCAD as a globally respected statistical agency, His Excellency is honoured and privileged to be the first in the Gulf region to host such a largescale international statistical event. Recognising the need for official statistics to keep users well informed and assist good policy and decision-making, he fully understands the importance of SCAD's role in galvanising the official statistics community in the Gulf region and further afield. The IAOS 2016 Conference will also provide the opportunity to promote Arabic culture and may pave the way for SCAD to host bigger events in the future, such as the ISI World Statistics Congress. SCAD will host the $15^{\text {th }}$ IAOS Conference at the Abu Dhabi National Exhibition Centre on 6-8 December 2016. For further information about $S C A D$, please visit www.scad.ae. For further information about IAOS 2016, please visit www.iaos2016.ae. 